\title{
Marketing health - In all but name
}

\author{
Hearts and mouths: perceptions of oral hygiene by at-risk heart surgery patients
}

R. J. Lowry, P. Maunder, J. G. Steele, J. Colligan, C. A. Beard, J. Harvey and G. Erdos BrDent J 2005; 199: 449-451

\section{Objective}

To assess and use the attitudes of patients who are placed at risk after valvular heart surgery due to the connection between poor oral hygiene, valvular heart disease/surgery and the risk of developing infective endocarditis.

Design

A qualitative (focus group) design based study carried out on subjects three months post heart surgery.

Method

There were five focus groups of five participants each convened by an experienced moderator.

Results

These portrayed an apparent pressing desire by most patients to talk about their experiences. However, patients did not accept the link between their oral health and their general health. Oral hygiene practices were not necessarily oral health related.

Conclusions

The importance of the study in understanding the reasons for a patient's behaviour is evident when there is a clear need to modify the behaviour patterns of the patients effectively. Clinical trials can now be developed based on these results.

\section{IN BRIEF}

- Patients attending heart surgery units are often at high risk of heart disease arising from poor oral hygiene, so this study provides valuable and novel insights.

- Oral health care professionals will be able to devise interventions that are successful using the data presented in this article.

\section{COMMENT}

In To kill a mockingbird, Atticus is seeking to explain to his daughter why people do seemingly hateful things to one another. He explains that: ' you never really understand a man until you consider things from his point of view, until you climb into his skin and walk around in it'. This paper by Lowry et al. proves how right he was, and how important his words remain for health professionals.

It discusses the serious health risks - specifically infective endocarditis - that can ensue if patients do not practise good oral hygiene following valvular heart surgery. The medical and biochemical side of this equation has been well researched: the link to oral hygiene is proven and the potentially lethal consequences well documented. Now, for the first time Lowry et al. have explored patients' views on the matter - and their work has forehead slapping implications.

First of all most patients have little notion that their oral hygiene can have such immediate and serious health consequences. Like most of us outside the dental profession, they see tooth care as having more to do with grooming than health. Given this, it is not surprising that they fail to behave as the dental hygienists would like - they have no reason to do so. Lowry et al. show us that we have to start from where people are, recognise that their perceptions differ from ours, and avoid making judgements.

They also remind us that emotion is an important behavioural driver. This should come as no surprise to $B D J$ readers; dentists, more than most health professionals, have to work with people's feelings - most typically in the form of fear. The researchers show how negative emotions discourage people from thinking about the undesirable consequences of their behaviour. However, they also show that emotions can be a force for good. The warmth patients feel towards their health professionals - and especially their surgeons - is palpable in the quotes. They rightly go on to argue that we should make the most of this opportunity.

They also recognise the strategic implications this has. It suggests a need not just for one-off information exchange, but for the development of professional-patient relationships. Dental hygienists can maximise their influence by using this very positive effect to develop long term trust, commitment and respect between them and their patients.

The process of listening to your customer, acknowledging their emotional as well as rational drivers and building mutually beneficial and respectful relationships with them is called social marketing. Their paper provides a welcome introduction to its potential.

G. Hastings, Institute for Social Marketing, Stirling and the Open University

doi: 10.1038/sj.bdj.4812745 